\title{
Chromosome 18q-Syndrome and $1 p$ terminal duplication in a patient with bilateral vesico- ureteral reflux: case report and literature revision
}

\author{
Elisa Brandigi", Francesco Molinaro, Anna Lavinia Bulotta, Rossella Angotti, Maria Pavone and Mario Messina
}

\begin{abstract}
Background: Vesico-ureteral reflux (VUR) is a dynamic event in which a retrograde flow of urine is present into the upper tracts. VUR may occur isolated or in association with other congenital abnormalities or as part of syndromic entities. We present a patient with a bilateral primary VUR, syndromic disease caused by a large deletion of $18 q$ (18q21.3-qter) and terminal duplication of $1 p(1 p 36.32-p 36.33)$.

Case report: The patient was 8 years old female with a disease including moderate growth retardation, psychomotor retardation, facial dysmorphism, single umbilical artery, umbilical hernia, urachal remnant, bilateral congenital clubfeet and renal-urinary disease. Chromosomal analysis and Array-CGH revealed two heterozygous chromosomal rearrangements: $1 p$ terminal duplication and de novo 18q terminal deletion. She referred to our clinic to evaluation of bilateral hydronephrosis and right renal cortex thinning. Voiding cystourethrography demonstrated bilateral grade IV VUR and dimercaptosuccinic acid renal scintigraphy confirmed right renal cortex thinning and showed a cortical uptake of $75 \%$ of the left kidney and $25 \%$ of the right kidney. The patient underwent ureterovesical reimplantation after failure of 3 endoscopic submeatal Deflux injections with VUR resolution.

Conclusions: This is the first report involving a patient with 18q-syndrome and contemporary presence of $1 p$ chromosomal terminal duplication. The coexistence of two chromosomal rearrangements complicates the clinical picture and creates a chimeric disorder (marked by characteristics of both chromosomal anomalies). Kidney problems, primarily VUR is reported in 15\% of patients affected by 18-q syndrome and no cases is reported in the literature regarding a correlation between VUR and 1p36 chromosomal duplication.
\end{abstract}

Keywords: Vesico-ureteral reflux, Deletion of 18q, Duplication of $1 p$

\section{Introduction}

Vesico-ureteral reflux (VUR) is the most common disease of the urinary tract in children and affecting approximately $1 \%$ of all children [1].

The primary reflux may occur isolated or in association with other congenital abnormalities of kidney/urinary tract or as part of syndromic entities [2].

Syndromic VUR has an inherited Mendelian trasmission [3]. Several congenital syndromes associated with VUR as Renal coloboma o Brachio-otorenal syndrome were know [2]. The $18 \mathrm{q}$ syndrome affecting the patient that we

\footnotetext{
* Correspondence: elisabrandigi@gmail.com

Division of pediatric surgery, department of pediatrics, obstetrics and reproductive medicine, University of Siena, Siena, Italy
}

present isn't included among these syndromes despite some cases presenting VUR have been reported [4].

The 18q-syndrome is chromosomal disorder resulting from a total or partial deletion of the long arm of chromosome 18 [5]. The syndrome constitutes one of the most frequent autosomal syndrome in man and the clinical phenotype is variable because the breakpoint varies greatly and it is generally characterized by mental retardation, development delay, short stature and a specific pattern of cranofacial dysmorphisms, hearing loss, neurologic abnormalities such hypoplasia, hands and feet anomalies $[5,6]$.

Chromosome $1 \mathrm{p}$ duplication is a very rare rearrangement and the most consistent manifestations are low birth weight, grow retardation, craniosynostosis, facial anomalies (flat nasal bridge, hiperthelorisme, cleft palade), hand malformation, congenital heart diseases [7]. 
We present a patient with a bilateral primary VUR, syndromic disease caused by a large deletion of $18 \mathrm{q}$ (18q21.3-qter) and terminal duplication of $1 \mathrm{p}(1 \mathrm{p} 36.32-$ p36.33).

To our knowledge no patient has so far been reported to be affected by both $18 \mathrm{q}$-syndrome and $1 \mathrm{p} 36$ duplication.

\section{Clinical report}

The patient was a 8 years old female and she was the second child of a healthy and non consanguineous couple. The first-born is healthy. The patient was born at 40 weeks gestation by a normal spontaneous vaginal delivery. Her birth weight was $2700 \mathrm{gr}$, birth length was $48 \mathrm{~cm}$ and her head circumference was $31 \mathrm{~cm}\left(<\mathrm{III}^{\circ}\right.$ percentile). She was noted at birth to have a single umbilical artery, umbilical hernia, renal-urinary disease and bilateral congenital clubfeet treated by an application of moulded plaster casts.

At the birth a renal ultrasonography was performed to evaluate an hydronephrosis discovered during a prenatal ultrasonography. The renal ultrasonography showed a bilateral hydronephrosis and right renal cortex thinning. Voiding cystourethrography (VCUG) demonstrated bilateral grade IV VUR and urachal remnant later treated by a surgical approach (Figure 1).
A renal dimercaptosuccinic acid (DMSA) scan performed at 6 months confirmed right renal cortex thinning and revealed a cortical uptake of $75 \%$ of the left kidney and $25 \%$ of the right kidney.

The patient was initially treated with endoscopic submeatal bilateral injection of $0.5 \mathrm{cc}$ Deflux at 30 months.

After this procedure, antibiotic prophylaxis (AP) with Cefixime $(10 \mathrm{mg} / \mathrm{Kg} /$ dose $)$ was administered until six month. During this period the patient didn't show UTI signs but her growth was retarded. When she was two and a half years old an UTI occurred with high fever and positive of urine culture. A VCUG confirmed persistent of left grade III VUR so, she was undertaken to a subsequent left injection of 0,6 cc of Deflux ${ }^{\circledR}$. Treatment with AP was continued and the result of urine culture performed every two months was negative. One year after this procedure a new VCUG was performed and the result is the same of the previous examination. For the persistent of a postoperative reflux she was undertaken at the age of five years old to a subsequent Deflux ${ }^{\circledR}$ injection with a failure of the treatment. The patient at 7 years of age was underwent with bilateral Glenn-Anderson's ureterovesical reimplantation with VUR resolution.

Standard karyotype was performed on peripheral blood lymphocytes from the patient and both parents with GAG, QFQ banding techniques.

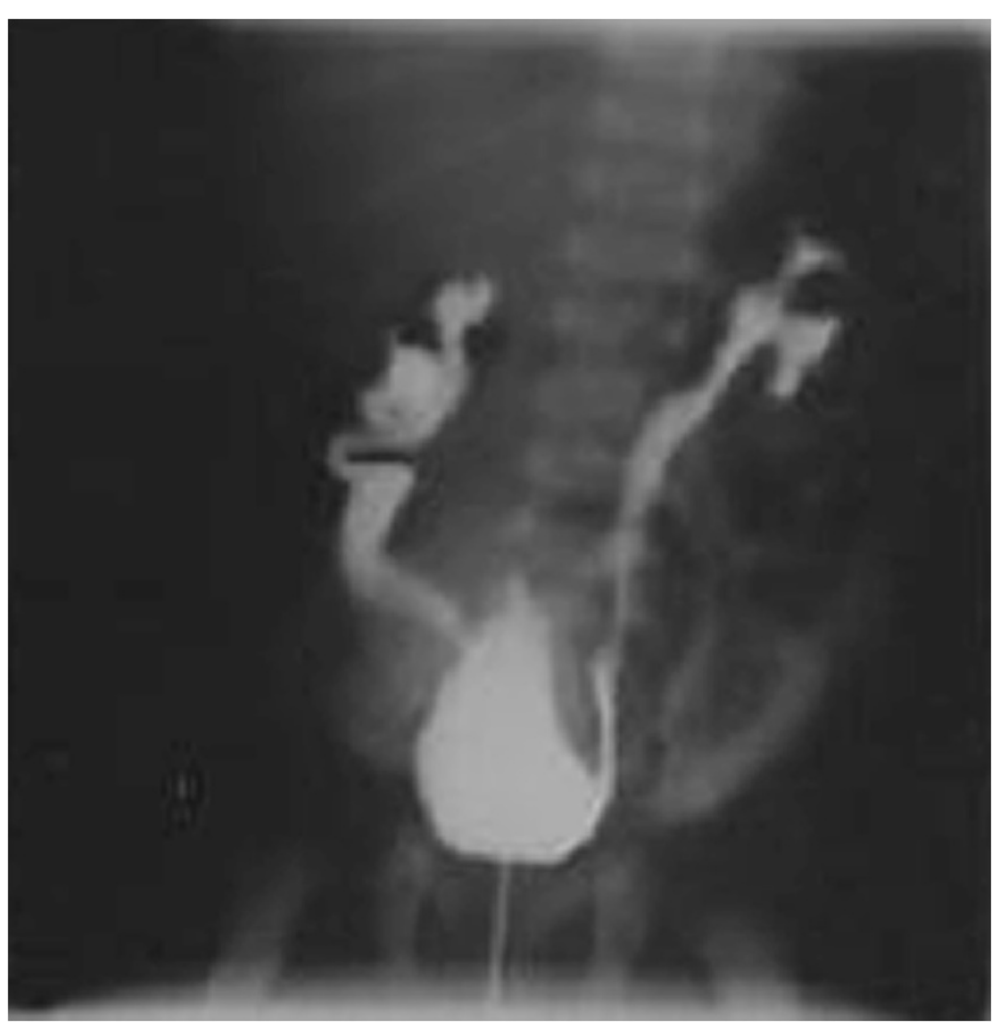

Figure 1 CUM imaging: IV ${ }^{\circ}$ grade bilateral VUR. 
The Karyotype designation was 46,XX,del(18) (q21.3->qter) occurred de novo, as both parents had normal karyotype. Subsequently Array-CGH was done with Agilent Human Genome CGH Microarray Kit 44B) and confirmed a del(18) (q21.3->qter) involving 53 genes in the one chromosome 18, but furthermore revealed the presence of a terminal duplication of $1 \mathrm{p}$ (1p36.32-p36.33) involving 74 genes.

Additional physical features included: growth retardation, hypotonia, brachycephaly, midface hypoplasia, wide spaced front, hyperthelorisme, micrognatia, wide philtrum, depressed and wide nasal bridge, small teeth, deep-set eyes with downslanting palpebral fissures, normal ears (Figure 2).

Her developmental milestones were delayed as she walked at the age of 2 years and 6 month, her first words were spoken at the age of 6 years.

Heart ultrasound, electroencephalogram, liver-spleen ultrasound, visual and audiological examination were all normal.

Our research is in compliance with the Helsinki Declaration and written informed consent was obtained from the patient for the publication of this report and any accompanying images.

\section{Discussion}

The 18q-syndrome is characterized by a deletion that involves the distal section of $18 \mathrm{q}$ and typically extends to the tip of the long arm. The breakpoint involved varies greatly and the presence or absence of specific clinical features may depend on the size and position of the deleted region [8]. The increasing use of molecular techniques such as array-CGH enables more accurate definition of the breakpoints. This, in turn, enables researchers to study which parts of the chromosome correlate with the different clinical features of the condition [9].

It is generally characterized by mental retardation, development delay, short stature, hearing loss, white matter abnormalities of the brain, neurologic abnormalities such hypoplasia, hands and feet malformation and ocular anomalies [5,6]. The facial dysmorphism may include brachycephaly, midface hypoplasia, everted lower lip, narrow upper lip with absent philtrum, downturned

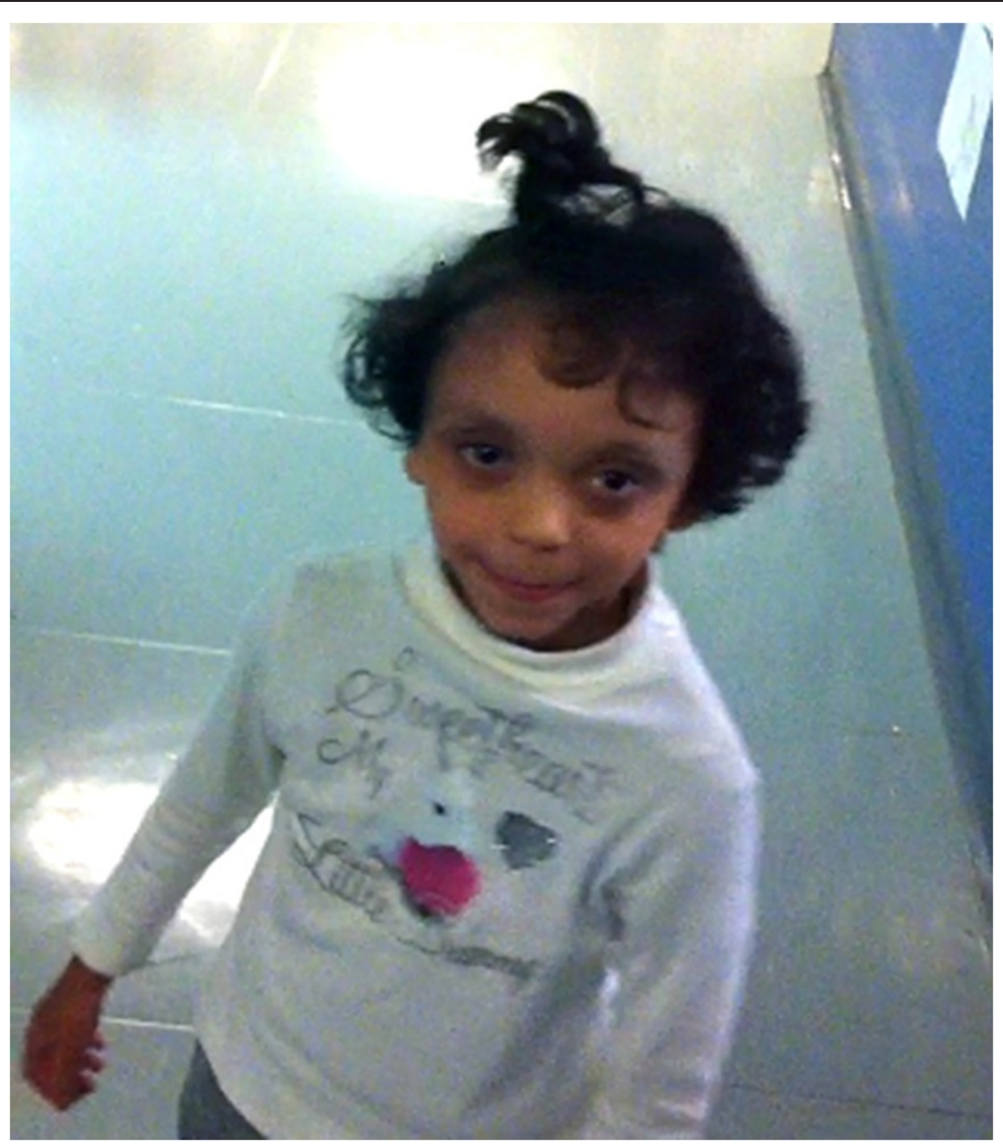

Figure 2 Facial features of the proband. 
corners of the mouth, depressed and wide nasal bridge, small teeth, deep-set eyes with downslanting palpebral fissures, epicanthus, strabismus, prominent anthelix and antitragus, and very narrow external ear canal [10]. The associated anomalies include vertebral anomalies, genitourinary changes, congenital heart defects, cleft lip and palate [10].

It is thought that the decreased growth may be due to a growth hormone deficiency. This region contains the genes myelin basic protein $(M B P)$ and the galanin receptor which are both candidates for the growth hormone insufficiency. The galanin receptor is involved in growth hormone response and is therefore a good candidate for the growth hormone insufficiency $[9,11]$. Interestingly, this region is almost identical to the region that has been identified to be responsible for the myelination problems. Thus, the gene or genes responsible for these two features are either the same gene or two tightly-linked genes. Up until now, all people who have been shown to have dysmyelination also have a growth hormone deficiency, so it has not yet been possible to uncouple these two features [9]. The common finding of narrow ear canals in 18q- has been linked, by three studies, to the loss of part of the region 18q22.3 [9,12].

A critical region for the microcephaly (small head) that is often present in 18q- has been shown to be located to band $18 q 21.33[8,9]$.

Chromosome 1p duplications have been reported rarely and his contribute to patient's phenotype it's difficult to estimate. A review of the literature suggests that there is not possible to establish a syndrome. The most consistent manifestations are low birth weight, grow retardation, craniofacial and hand anomalies, and congenital heart disease. Most males had abnormal genitalia, whereas females had normal genitalia [7]. Apart from not specific features such as microcephaly, growth retardation, and developmental delay, the most striking feature reported in previous studies is metopic, sagittal and coronal synostosis [13].

Such opposing phenotypes, cranial synostosis in $\operatorname{dup}(1)$ (p36)and large late closing anterior fontanels in $\operatorname{del}(1)(\mathrm{p} 36)$ is probably corraleted to a gene that regulates suture closure at chromosome 1p36 [13]. Chromosome 1p36 rearrangements have been associated also with various neoplasms such as neuroblastoma suggesting that 1 p36 region contain a tumor-suppressor gene involved in malignancy [13].

The coexistence of two chromosomal rearrangements complicates the clinical picture and creates a chimeric disorder marked by characteristics of both chromosomal anomalies.

The patient reported presents not specific characteristics like growth and psychomotor retardation and also feet malformation and microcephaly found in both anomalies.

The most clinical features as hypotonia, midface hypoplasia, micrognatia, wide philtrum, small teeth, deep-set eyes with downslanting palpebral fissures, umbilical hernia and RVU are related to $18 \mathrm{q}$ deletion syndrome.

The patient also present hyperthelorisme, depressed and wide nasal bridge probably related to 1 p36.3 duplication.

Patient's clinical phenotype isn't completely superimposable to the one present in $18 \mathrm{q}$ syndrome, for example, hearing abnormality, one of the most consistent features with 66 per cent of children affected, it is absent in this patient. This is probably consequent to the great breakpoint variability and to the simultaneous presence of $1 p$ duplication.

Concerning VUR for which the patient referred to our clinic, most researchers now acknowledge that VUR is genetically heterogeneous [2].

The initial evidence suggesting a genetic origin of primary VUR came from twin studies, showing an 80\%-100\% concordance for VUR in monozygotic twins vs. a $35-50 \%$ concordance in dizygotic twins [2].

Studies of humans with chromosomal abnormalities suggest for not syndromic primary VUR candidate loci or genes on chromosomes 6p, 10q26, 19q13 and 13q33-34 [2].

M.L. Conte et al showed best evidence of linkage with VUR on chromosome 3 p12.3-3q24 and on chromosome 1p36.32-1p34.3.

None of 13 reported patients affected by chromosome 1 p36 terminal duplications evidenced the presence of VUR.

No part of the chromosome 18 has yet been identified related to VUR despite is reported approximately in 15\% of patient affected by syndrome 18q.

\section{Conclusion}

The clinical case discussed it is the first reported to be affected by both 18q-syndrome and 1p36 duplication (despite some children with 18q-syndrome have the involvement of an additional chromosome, usually a duplication of material from another chromosome).

The coexistence of two chromosomal rearrangements complicates the clinical picture and creates a chimeric disorder marked by characteristics of both chromosomal anomalies.

Chromosome 1p duplications is a rare anomaly with only 13 cases reports in literature his contribute to patient's phenotype it's difficult to estimate [6].

Concerning VUR that interest the syndromic disease presented, we know that none of 13 reported patients affected by chromosome 1p36 terminal duplications evidenced the presence of VUR and no part of the chromosome 18 has yet been identified related to VUR despite is reported approximately in $15 \%$ of patient affected by syndrome $18 \mathrm{q}$.

Most researcher now acknowledge that VUR is genetically heterogeneous and no more these loci or genes has been shown causally related to primary VUR. 
Continuous increasing knowledge of the genetic basis of VUR should help us to further understand its pathogenesis.

\section{Consent}

"Written informed consent was obtained from the patient's guardian/parent/next in keen for publication of this report and any accompanying images".

\section{Competing interests}

The authors declare that they have no competing interests.

\section{Authors' contributions}

All authors read and approved the final manuscript.

Received: 7 October 2012 Accepted: 8 January 2013

Published: 23 January 2013

\section{References}

1. Hsieh MH, Madden-Fuentes RJ, Lindsay NE, Roth DR: Treatment of pediatric vesicoureteral reflux using endoscopic injection of hyaluronic acid/dextranomer gel: intermediate-term experience by a single surgeon. Urology 2010, 76(1):199-203.

2. Conte ML, Bertoli-Avella AM, de Graaf BM, Punzo F, Lama G, La Manna A, Grassia C, Rambaldi PF, Oostra BA, Perrotta S: A genome search for primary vesicoureteral reflux shows further evidence for genetic heterogeneity. Pediatr Nephrol 2008, 23(4):587-595.

3. Morales Martínez A, Calvo Medina R, Chaffanel Peláez M, Bueno Fernández A, Míguelez Lago C, Acedo del Olmo EC: Embryology and genetics of primary vesicoureteral reflux and associated renal dysplasia. Arch Esp Urol 2008, 61(2):99-111.

4. Puri P, Gosemann JH, Darlow J, Barton DE: Genetics of vesicoureteral reflux. Nat Rev Urol 2011, 8(10):539-552.

5. Kohonen-Corish M, Strathdee G, Overhauser J, McDonald T, Jammu V: A new deletion of $18 \mathrm{q} 23$ with few typical features of the $18 \mathrm{q}-$ syndrome. J Med Genet 1996, 33(3):240-243.

6. Dostal A, Nemeckova J, Gaillyova R: The 18q deletion syndrome and analysis of the critical region for orofacial cleft at 18q22.3.

J Craniomaxillofac Surg 2009, 37(5):272-275.

7. Garcia-Heras J, Corley N, Garcia MF, Kukolich MK, Smith KG, Day DW: De novo partial duplications 1p: report of two new cases and review. Am J Med Genet 1999, 82(3):261-264.

8. Kline AD, White ME, Wapner R, Rojas K, Biesecker LG, Kamholz J, Zackai EH, Muenke M, Scott CI Jr, Overhauser J: Molecular analysis of the 18q- syndrome and correlation with phenotype. Am J Hum Genet 1993, 52(5):895-906. Review.

9. Feenstra I, Vissers LE, Orsel M, van Kessel AG, Brunner HG, Veltman JA, van Ravenswaaij-Arts CM: Genotype-phenotype mapping of chromosome 18q deletions by high-resolution array CGH: an update of the phenotypic map. Am J Med Genet A 2007, 143A(16):1558-1567.

10. : High-resolution array CGH: an update of the phenotypic map. Am J Med Genet A 2007, 143A(16):1858-1867.

11. Manolakos E, Kosyakova N, Thomaidis L, Neroutsou R, Weise A, Mihalatos M, Orru S, Kokotas H, Kitsos G, Liehr T, Petersen MB: Complex chromosome rearrangement in a child with microcephaly, dysmorphic facial features and mosaicism for a terminal deletion del(18)(q21.32-qter) investigated by FISH and array-CGH: Case report. Mol Cytogenet 2008, 1:24.

12. Ghidoni PD, Hale DE, Cody JD, Gay CT, Thompson NM, McClure EB, Danney MM, Leach RJ, Kaye Cl: Growth hormone deficiency associated in the $18 \mathrm{q}$ deletion syndrome. Am J Med Genet 1997, 69(1):7-12.

13. Tonk VS, Wilson GN, Yatsenko SA, Stankiewicz P, Lupski JR, Schutt RC, Northup JK, Velagaleti GV: Molecular cytogenetic characterization of a familial der(1)del(1)(p36.33)dup(1)(p36.33p36.22) with variable phenotype. Am J Med Genet A 2005, 139A(2):136-140.

doi:10.1186/1824-7288-39-6

Cite this article as: Brandigi et al.: Chromosome 18q-Syndrome and $1 \mathrm{p}$ terminal duplication in a patient with bilateral vesico-ureteral reflux: case report and literature revision. Italian Journal of Pediatrics 2013 39:6.

\section{Submit your next manuscript to BioMed Central and take full advantage of:}

- Convenient online submission

- Thorough peer review

- No space constraints or color figure charges

- Immediate publication on acceptance

- Inclusion in PubMed, CAS, Scopus and Google Scholar

- Research which is freely available for redistribution 